\title{
An Innovative Product for Pain Management: Proof from Clinical Trial
}

Aruna $\mathbf{V}^{*}$, Abdul A, Amruthavalli GV and Gayathri R

Dr JRK's Siddha Research and Pharmaceuticals Pvt Ltd, No18 \& 19 Perumal Koil street, Kunrathur, Chennai, India

*Corresponding author: Aruna V, Assistant Manager Production and Quality Control, Dr JRK's Siddha Research and Pharmaceuticals Pvt Ltd, No18 \& 19 Perumal Koil street, Kunrathur, Chennai-600069, India, Tel: 9566165310; Fax: 09566165310; E-mail: research@jrksiddha.com

Received date: February 27, 2017; Accepted date: March 08, 2017; Published date: March 15, 2017

Copyright: (c) 2017 Aruna V, et al. This is an open-access article distributed under the terms of the Creative Commons Attribution License, which permits unrestricted use, distribution, and reproduction in any medium, provided the original author and source are credited.

\begin{abstract}
The present article deals with innovation and therapeutic efficacy of Akshun -bathing lotion for pain relief a proprietary Siddha drug. The clinical trial findings show that the product possess pain relieving effect and which was reported by the patients suffered from cervical spondylitis, low back pain and pain in the joints; participated in the trial. Further the period of relief was stated to be 5 hours. The findings clearly indicate the likely role of Akshunbathing lotion for pain relief. The findings further suggest it's role not only in the management of pain but also for reducing the drug dependency of various steroidal and non-steroidal analgesic drugs which in turn may result in less toxic side effects from these drugs. Findings are discussed in the paper.
\end{abstract}

Keywords: Pain management; Cervical spondylitis; Cleanser; Drug dependency

\section{Introduction}

The quality of life is greatly affected by acute and or chronic pain due to cervical spondylitis and other degenerative causes [1,2]. Such chronic pain doesn't limit in affecting the morbidity of the patients but also pose a challenge to medical fraternity.

Due to the fast changing lifestyle, food habits, occupational pressure and tension these days' bars no age group from succumbing to various degenerative disorders $[3,4]$. As a result, the problems like cervical spondylitis, low back pain, and pain in the joints are seriously affecting people even at the age group of 15 years to 20 years, whereas once the above problems was quite endemic among elderly people [5-7].

Although lifelong treatment is essential for the above problems but total cure is still elusive and evasive. Steroidal and non-steroidal analgesics are largely used to manage the pain [8]. Prolonged usage of above drugs warrants higher dosage due to possible tachyphylaxis. Prolonged usage of various analgesic preparations known to produce serious side effects such as gastritis, renal complications, liver toxicity etc [9].

Managing the agonizing pain and at the same time, minimizing the dependency on the analgesic drugs is extremely challenging and is important especially for those who suffer from chronic pain and also from various side effects [10].

To reduce the dependency of oral analgesic preparations, a holistic therapy approach is essential. The holistic approach must include fast acting cleansers with analgesic effects for managing the pain. Most of the chronic sufferers of pain do use wide variety of topical pain relieving products, mostly oils. Therefore a cleanser with an analgesic effect will certainly provide both the cleansing need as well as relief from pain. The present article deals with both the product innovation of Akshun- bathing lotion for pain relief and its efficacy which was established by clinical trial.

\section{Materials and Methods}

Akshun- bathing lotion for pain relief is a proprietary Siddha medicine of Dr. JRK's Siddha Research and Pharmaceuticals. This medicine is formulated with therapeutically effective herbs that are well documented in the ancient scriptures of Siddha system of medicine such as

\section{1) Clerodendron phlomoides \\ 2) Cardiospermum helicacabum \\ 3) Cinnamamonum camphora \\ 4) Mentha piperata}

The formulation base is composed of fatty acids that were obtained out of saponification of saturated long chain fatty acids.

The Siddha drug; Akshun - bathing lotion for pain relief has great dissolution quotient in water, as a result, the pre-engineered herbs could easily permeate and are likely to enhance the heamodynamic profile of the skin resulting in quick and long lasting analgesic effect.

\section{Details of the clinical trial}

The clinical trial was done by Quest Life Sciences Pvt., Ltd., SDF III, III Floor, MEPZ, Tambaram, Chennai and the clinical trial was done fully in compliance with all regulatory and ethical norms with the following reference- CTRI No- REF/2016/10/012398.

\section{Details of inclusion and exclusion criteria of patients \\ Inclusion criteria}

1) Availability of the patients for the entire study period and willingness to adhere to the protocol requirements as evidenced by written informed consent form (ICF) duly signed by the patient.

2) Patients in the age group between 18 to 75 years, both male and female. 
3) Patients who had no evidence of life-threatening disease during screening, medical history and also the physical examination are performed within 28 days prior to commencement of the study.

4) Patients suffering from cervical spondylitis, low back pain or pain in the joints of chronic nature.

5) Patients, who are willing to avoid sun bath, swimming, prolonged sun exposure or artificial UV rays during the study.

\section{Exclusion criteria}

1) Patients suffering from acute and sudden pain.

2) Patients who are allergic to cosmetics, moisturizers, and whitening/bleaching agents.

3) Patients who suffer from sunburned, chapped, or irritated skin or open wounds on test sites.

4) Patients who are not willing to discontinue the use of the personal care products contain whitening/bleaching agents during study period.

5) History of skin cancer or treatment for any type of cancer within the last 2 years.

6) Medical history shows any significant dermatologic diseases or conditions, such as atopy, psoriasis, acne, eczema, atopic dermatitis, vitiligo or conditions known to alter skin appearance or physiologic response (e.g. porphyria).

\section{Problem definition}

Patients were recruited with the following medical problems such as

1: Cervical spondylitis

2: Low back pain and

3: Pain in the joints of chronic duration

\section{Study procedure}

The Siddha drug was given to the patients during their second visit (After recruitment and signing of ICF) of the trial. All the patients were instructed to use the Siddha drug for bathing/washing the painful surface on every alternative day for a period of 2 weeks i.e. 7 times.

The patients were further advised to use either warm or cold water for bathing according to their choice and preference. However, patients were instructed to allow the drug to remain in the skin for 5 minutes before bathing. Each patient was requested to report the extent of relief of pain under the following caption such as

1: Very Good Relief- Significant improvement

2: Good Relief- Moderate improvement

3: No change

4: Much worse than before

As well as the duration of relief viz.,

A: 1 hour after use

B: more than 1 hour

C: more than 5 hours
Assessment: The clinical assessment was done based on the clinical examination of the patients as well as capturing the self- assessment of the patients with reference to extent and duration of relief.

During each visit, the patients were requested to inform the investigator about the status of pain post use of the drug and the details were recorded by the investigator. The physician's global assessment pattern (PGA) scale was used for evaluation (Figure 1).

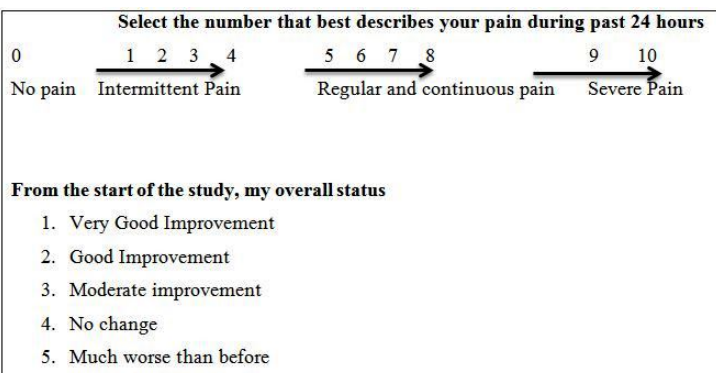

Figure 1: PGA scale.

\section{Statistical analysis}

25 Subjects both male and female in the age between 18 to 75 with chronic condition of cervical spondylitis and low back pain and joints pain were included in the study. The data were most representative of the types of subjects with chronic nature referred to cervical spondylitis, low back pain, pain in the joints for pain management. Initial analysis consisted of descriptive statistics of age (frequencies, means, medians, and standard deviations) were calculated for continuous variables. The Chi-square test was used to compare the pain severity with Categorical outcomes. Chi-square analyses were performed to identify the significance of the pain severity level and frequency and percentage for gender. Inference was given by applying statistical hypothesis tests and the significant results were provided using SAS version 9.4/Enterprise Guide 6.1 at Quest life sciences Pvt. Ltd. The statistical analysis for Akshun - Bathing Lotion for Pain Relief was performed by Chi-square test (SAS 9.4/ Enterprise guide 6.1).

\section{Results}

Among the 25 patients participated in the study 7 patients were female and rest were male. The predominant age group of patient participated in the study were between 20 to 30 (Table 1).

\begin{tabular}{|l|l|l|l|}
\hline \multirow{2}{*}{ Gender } & \multicolumn{4}{l|}{ Age in years/ number of patients } \\
\cline { 2 - 4 } & $20-30$ & $31-40$ & $41-50$ \\
\hline Male & 10 & 4 & 4 \\
\hline Female & 1 & 2 & 4 \\
\hline
\end{tabular}

Table 1: Age and gender distribution of patients participated in the study.

Among the 25 patients participated in the study 18 patients reported to suffer from Regular and continuous pain and seven patients with intermittent pain (Table 2). 
Citation: Aruna V, Abdul A, Amruthavalli GV, Gayathri R (2017) An Innovative Product for Pain Management: Proof from Clinical Trial. J Pain Manage Med 3: 123.

Page 3 of 5

\begin{tabular}{|c|c|c|}
\hline \multirow{2}{*}{ Gender } & \multicolumn{2}{|c|}{ Details of the pain/number of patients } \\
\cline { 2 - 3 } & Intermittent pain & Regular and continuous pain \\
\hline Male & 6 & 12 \\
\hline Female & 1 & 6 \\
\hline
\end{tabular}

Among the 25 patients, 8 patients (32\%) reported to have relieved from pain for more than 5 hours of the application of the Siddha drug and 16 patients $(64 \%)$ reported to have relieved from pain from more than 1 hour of the application of the Siddha drug (Tables 3 and 4).

Table 2: Classification of patients with reference to pain.

\begin{tabular}{|c|c|c|c|c|c|c|}
\hline \multirow{3}{*}{ Usage } & \multicolumn{6}{|c|}{ Clinical assessment } \\
\hline & \multicolumn{2}{|c|}{ Very good improvement } & \multicolumn{2}{|c|}{ Good improvement } & \multicolumn{2}{|c|}{ No improvement } \\
\hline & IP & $\mathrm{RCP}$ & IP & $\mathrm{RCP}$ & $\mathrm{IP}$ & $\mathrm{RCP}$ \\
\hline 1 & - & - & - & 2 & - & - \\
\hline 3 & 1 & 2 & 1 & 6 & - & - \\
\hline 5 & 1 & 1 & 1 & 5 & - & 1 \\
\hline 7 & - & - & 3 & 1 & - & - \\
\hline
\end{tabular}

Table 3: Clinical assessment on extent of relief vis-à-vis usage.

\begin{tabular}{|l|l|l|l|}
\hline Statistic & DF & Value & Prob \\
\hline Chi-Square & 6 & 7.1094 & 0.3109 \\
\hline Likelihood Ratio Chi-Square & 6 & 6.7611 & 0.3435 \\
\hline Mantel-Haenszel Chi-Square & 1 & 3.3409 & 0.0676 \\
\hline Phi Coefficient & - & 0.5333 & - \\
\hline Contingency Coefficient & - & 0.4705 & - \\
\hline Cramer's V & - & 0.3771 & - \\
\hline
\end{tabular}

Chi-square test: Categorical outcomes were compared across Pain severity level using a Chi-square test. Duration of relief from pain after the application of Investigational product was defined as 1 hour, more than 1 hour and more than 5 hour. Statistical significance was evaluated at the 0.05 level.

Among the 25 patients, 5 patients (20\%) have reported very good improvement and 19 patients (76\%) have reported good improvement. i.e., the effect was significant when compared to the pain during the past 24 hours.

Chi-square test: Categorical outcomes were compared across pain during the past 24 hours (Intermittent Pain and Regular and continuous pain) and overall status on the extent of relief after the application of Siddha drug was defined as 'Very Good Improvement', 'Good Improvement' and 'No Change' (Table 5).

Table 4: Chi-square test-The number of usage of the product an duration of relief.

\begin{tabular}{|c|c|c|c|}
\hline \multirow{2}{*}{$\begin{array}{l}\text { Status } \\
\text { Frequency Percent Row Pct Col Pct }\end{array}$} & \multicolumn{3}{|l|}{ Past } \\
\hline & Regular and Continuous pain & Intermittent Pain & Total \\
\hline \multirow{4}{*}{ Very Good Improvement } & 3 & 2 & 5 \\
\hline & 12 & 8 & 20 \\
\hline & 60 & 40 & - \\
\hline & 16.67 & 28.57 & - \\
\hline \multirow{4}{*}{ No Change } & 1 & 0 & 1 \\
\hline & 4 & 0 & 4 \\
\hline & 100 & 0 & - \\
\hline & 5.56 & 0 & - \\
\hline Good Improvement & 14 & 5 & 19 \\
\hline
\end{tabular}




\begin{tabular}{|c|c|c|c|}
\hline & 56 & 20 & 76 \\
\hline & 73.68 & 26.32 & - \\
\hline & 77.78 & 71.43 & - \\
\hline \multirow{2}{*}{ Total } & 18 & 7 & 25 \\
\hline & 72 & 28 & 100 \\
\hline
\end{tabular}

Table 5: Comparison of pain during past 24 hours and overall status after application of Akshun- bathing lotion for pain relief.

Among the 25 patients, 5 patients (20\%) have reported very good improvement and 19 patients (76\%) have reported good improvement. i.e., the effect was significant when compared to the pain during the past 24 hours (Table 6).

\begin{tabular}{|l|l|l|l|}
\hline Statistic & DF & Value & Prob \\
\hline Chi-Square & 2 & 0.7728 & 0.6795 \\
\hline Likelihood Ratio Chi-Square & 2 & 1.0169 & 0.6014 \\
\hline Mantel-Haenszel Chi-Square & 1 & 0.2494 & 0.6175 \\
\hline Phi Coefficient & - & 0.1758 & - \\
\hline Contingency Coefficient & - & 0.1732 & - \\
\hline Cramer's V & - & 0.1758 & - \\
\hline
\end{tabular}

Table 6: Chi-square test for Table of pain during past 24 hours and overall status after the application of Akshun- bathing lotion for pain relief.

\section{Discussion}

Findings of the clinical trial have not only validated the therapeutic superiority of the proprietary Siddha drug (Akshun- bathing lotion for pain relief) but also the product uniqueness and innovation i.e., bathing lotion for pain relief. For the management of chronic pain, a multi- prong strategy is needed.

Unlike the scientifically proven allopathic system of medicine, Siddha system of medicine is rooted in holistic health care approach. The holistic healthcare approach essentially includes the use of oral herbo- mineral- metal preparations, total herbal preparations and internal and topical use of oils besides massage therapy and some tailor made yoga asana. However offering relief to pain through a cleansing preparation or the delivery of 'pain relief' through a cleanser is never being discussed or used in Indian system of Medicine such as Ayurveda, Siddha, Unani or Homeopathy.

The patients participated in the clinical trial were chronic sufferers of pain such as cervical spondylitis, low back pain and pain in the joints. The present Siddha drug has significantly reduced the intensity of pain as well as freedom from pain for a period of maximum five hours. This suggests that continuous use of Akshun- bathing lotion for pain relief may help the patient to reduce their over dependency on analgesic drugs. By wise and prudent use of Akshun- bathing lotion for pain relief, the patients can possibly minimize the dosage of the analgesic drugs that they are using and also could avoid the usage of such drugs, at times.
The chronic sufferers of pain certainly requires alternative pain relief products to safe guard their system from the possible side effects. If such alternative products have great ease of use, doesn't stay long and contributes to some cumulative absorption and can be easily removed will certainly serve great value for the management of chronic pain. In that respect, the innovation and the proven therapeutics of Akshun- bathing lotion for pain relief assumes great medical importance for managing chronic pain. The use of tropical oils, ointments etc., also can be avoided wherever possible with the help of Akshun- bathing lotion for pain relief.

The product innovation and proven therapeutics of Akshunbathing lotion for pain relief also points towards another long lasting benefit to the patients. Most of the patients who suffer from chronic pain do maintain a cupboard full of various pain relief products. Over stocking and procurement of such product can be easily avoided in future with the help of Akshun- bathing lotion for pain relief.

The performance of Akshun- bathing lotion for pain relief is not altered by lukewarm or cold water used for bathing. However use of lukewarm water is highly desired.

The present Siddha drug being a bathing lotion and when it is used for bathing, its permeation into the skin through larger surface area of the body other than the region that's suffer from inflammation and pain is quite high and thus it can give overall wellbeing and body mind harmony instantaneously. Balancing the body- mind harmony is one of the treatment maxims of Siddha system of medicine.

The conventional steroidal and non- steroidal analgesic drugs used for the acute and chronic pain management are Ibuprofen which is a non-steroidal anti-inflammatory drug (NSAID) and is marketed under various trademarks including Act-3, Advil, Brufen, Motrin, Nuprin, and Nurofen. It is used for relief of symptoms of arthritis, primary dysmenorrhoea, and fever; Ibuprofen is an NSAID which is believed to work through inhibition of cyclooxygenase (COX), thus inhibiting prostaglandin synthesis. There are at least 2 variations of cyclooxygenase (COX-1 and COX-2); ibuprofen inhibits both COX-1 and COX-2. It appears that it's analgesic, antipyretic, and antiinflammatory activities are achieved principally through COX-2 inhibition; whereas COX-1 inhibition is responsible for its unwanted effects on platelet aggregation and the GI mucosa. As with other NSAIDs, ibuprofen inhibits platelet aggregation, but is not used therapeutically for this action since it is a minor and reversible effect.

The steroidal anti-inflammatory drugs include wide variety of steroids that block the immune response. In comparison with NSAID and SAID the mechanism of action of Akshun- bathing lotion for pain relief is not clearly known. However the active ingredients of of Akshun- bathing lotion for pain relief such as Clerodendron phlomoides, Cardiospermum helicacabum, Cinnamamonum 
Citation: Aruna V, Abdul A, Amruthavalli GV, Gayathri R (2017) An Innovative Product for Pain Management: Proof from Clinical Trial. J Pain Manage Med 3: 123.

Page 5 of 5

camphora, Mentha piperata are known to have counter- irritant property and can increase vasodilation and haemodynamics.

The clinical trial findings clearly suggests the possibility of Akshunbathing lotion for pain relief to likely revolutionize the pain management and enhance the overall feeling of wellbeing of the patients who suffer from agonizing pain for years.

\section{References}

1. Vos C, Verhagen A, Passchier J, Koes B (2007) Management of acute neck pain in general practice: a prospective study. Br J Gen Pract 57: 23-28.

2. Hardy, Paul AJ (1997) Chronic pain management: the essentials. U.K.: Greenwich Medical Media. ISBN.

3. Penning L, Wilmink JT, van Woerden HH, Knol E (1986) CT Myelographic Findings in Degenerative Disorders of the Cervical Spine: Clinical. American Roentgen Ray Society. 146: 793-801.

4. Roh JS, Teng AL, Yoo JU, Davis J, Furey C, et al. (2005) Degenerative disorders of the lumbar and cervical spine. Ortho Clini of N Amer, 36: 255-262.
5. Okada E, Matsumoto M, Ichihara D, Chiba K, Toyama Y, et al. (2009) Aging of the cervical spine in healthy volunteers: a 10-year longitudinal magnetic resonance imaging study. Spine 34: 706-712.

6. Hoving JL, de Vet HC, Twisk JW, Devillé WL, van der Windt D, et al (2004) Prognostic factors for neck pain in general practice. Pain 110: 639-645.

7. American Academy of Pediatrics (2001) The assessment and management of acute pain in infants, children and adolescents. Pediatrics 108: 793-797

8. Weiss SC, Emanuel LL, Fair Clough DL, Emanuel EJ (2001) Understanding the experience of pain in terminally ill patients. Lancet 357: 1311-1315

9. Melissa Vyvey (2010) Steroids as pain relief adjuvants. Can Fam Physician 56: 1295-1297.

10. Roosy A, Surjit S (2008) Strategies for minimizing corticosteroid toxicity: A Review. Indian J Pediatr 75: 1067-1073. 